\title{
Corrigendum: Control of cerebral ischemia with magnetic nanoparticle
}

Jie-Min Jia, Praveen D Chowdary, Xiaofei Gao, Bo Ci, Wenjun Li, Aditi Mulgaonkar, Erik J Plautz, Gedaa Hassan, Amit Kumar, Ann M Stowe, Shao-Hua Yang, Wei Zhou, Xiankai Sun, Bianxiao Cui \& Woo-Ping Ge

Nat. Methods 14, 160-166 (2017); published online 12 December 2016; corrected after print 10 April 2017

In the version of this article initially published, the middle cerebral artery was incorrectly referred to as the middle carotid artery. The error has been corrected in the HTML and PDF versions of the article as of 10 April 2017.

\section{Corrigendum: Massively parallel single-amino-acid mutagenesis}

Jacob O Kitzman, Lea M Starita, Russell S Lo, Stanley Fields \& Jay Shendure

Nat. Methods 12, 203-206 (2015); published online 5 January 2015; corrected after print 10 April 2017

In the version of this article initially published, the unit (nM) for the dUTP concentration described in the "Wild-type template preparation" section of the Online Methods was incorrect. The correct unit should be $\mu \mathrm{M}$. The error has been corrected in the HTML and PDF versions of the article as of 10 April 2017. 